\title{
Workhouse to Nursing Home: Residential Care of elderly people in England since I 840
}

\author{
DAVID THOMSON*
}

\section{ABSTRACT}

Statistics of the movement of elderly people through institutions of care have attracted little attention from present-day researchers, and none at all from historians. The intention in this paper is to indicate some of the analyses which the historian can make, to explore the changes and continuities in the inmate populations of institutions over I 20 years, and to speculate upon the reasons for the higher and lower incidences of residential care amongst the old in specific periods. The questions of interest here are how many and which groups amongst the old have been in care in different periods; how many people would ever find their way into institutions in old age: at what ages would they enter; for how long would they stay in care; would they die in care or leave for other reasons; what are the reasons for taking the elderly in to care; and what does all this tell us about the society in question.

Care of elderly people in earlier times has yet attracted very little scholarly attention, with the result that impressions of old age in the British past remain dominated by two vague, popular and often contradictory myths. The first of these is that 'in the past' families looked after the very few persons who managed to survive into old age. According to this oft-met wisdom nursing homes, geriatric hospitals and the like were not needed, because people knew and did their duty towards the old. The elderly of the past are assumed to have existed at some cosy heart of family life, surrounded by caring relatives who would ensure that 'our gran' continued to feel needed, useful and appreciated. Institutions for the care of the old find no place in this 'Golden Era' of old age.

* Department of History, Victoria University of Wellington, New Zealand. 
The second of the popular myths about old age in the past is that the elderly who did not enjoy private means ended their lives in institutions, the dreaded workhouses of the Poor Law. 'Workhouse' was the official name of a Poor Law institution in England between I 834 and 1929 . Similar institutions had existed in the country for at least two centuries before the reforms of 1934 , under such names as 'poorhouse', 'Charity House' and 'house of industry', and they were to continue in operation as 'Public Assistance Institutions' until the abolition of the Poor Law in $1948 .{ }^{1}$ One of the primary functions of a workhouse in all eras was the provision at public expense of a modicum of food, shelter, warmth and care for the disabled and destitute of the community, and since aged persons were always to be found amongst the disabled and destitute, the elderly found their way into these institutions. Admission to a workhouse was 'voluntary', in that the law did not allow the elderly to be admitted or detained forcibly, and no person who was without apparent means of support was to be denied admission, whatever his or her character or circumstances.

In this paper the intention is to consider both of these myths of old age in the past, together with much more, by way of an examination of the movements of elderly persons through institutions over the past I 20 years. ${ }^{2}$ What did workhouses amount to as a provision for old age? How big and crowded were they? How many aged persons went into them, at what ages, for how long and for what reasons? And how much has changed? The pity of this last question is that there is still too little information available upon institutions and their populations today with which the historian may compare his findings,

The paper will deal firstly with the information which can be drawn from published sources. Next, some simple analyses of several cohorts of ageing persons are discussed, as these groups of people moved through one particular institution. The paper ends with a comment upon some of the more important trends detected, and the possible links between these. The materials referred to are all English, but since Poor Law institutions akin to the English workhouse were found in many European countries, in North America, and in several of the new European colonial societies of the nineteenth century, the questions raised here must have a pertinence which stretches far beyond the social history of England. 


\section{The published historical record}

Our opening date of 1840 is forced upon us by the nature of the surviving records. During the 1830 , in a development which was connected with the reform of the Poor Laws amongst other things, an historic and crucial revolution occurred in the standards of public enquiry and record-keeping in Britain. That significant decade saw the national census assume its modern form, the initiation of civil registration of births, deaths and marriages, the founding of numerous Statistical Societies, and an unprecedented expansion in the scope and quality of governmental investigation. Poor Law records at both the central and the local level began to be kept on a new, regularised and rigorous scale, with numerous aspects of administration coming under detailed scrutiny. The outcome of this revolution is that we can learn a good deal about the workhouses from the 1830 s on, but that we can still know little of their lives before that date.

The quality of the post- 1830 secords varies enormously. Workhouse Masters were responsible for keeping an astonishingly comprehensive track of the lives of their institutions, but the attention devoted to this mountainous clerical task depended upon the diligence and cast of mind of the Master, together with the vigilance or casualness of his employers, the locally elected Board of Poor Law Guardians. ${ }^{3}$ Lapses in bookkeeping did occur for long periods, but a discernible improvement in workhouse records can be traced through the nineteenth century. Central government reports and compilations of Poor Law statistics, on the other hand, declined in quality from the 1850 , and the trend was never really reversed before the Poor Law's demise. After an initial enthusiasm in the 1830 and 1840 os for the gathering of statistics, the interest of the Poor Law authorities waned badly. Whole series of statistics ceased to appear in published reports, while others were collapsed into a few tabulations of a generality which renders them useless. A wish to disguise the workings of the Poor Law must be suspected. The effect of this is that we can often learn more about the workhouses of 1850 than we can those of 1900 or 1940 , perhaps even of their successor institutions in the r 960 s and 1970 .

\section{Size of Institutions}

The size of institutions is an obvious starting point for our discussion. The workhouses of the nineteenth century were small by the standards of twentieth-century institutions, although they were comparable in 
scale to the hospitals and lunatic asylums of their day. In the 1850 s there were an average of almost 300 bed-spaces - not necessarily beds - in the English workhouses. More than half of the institutions had fewer than 300 bed-spaces, and $\mathrm{I}$ in 8 had accommodation for fewer than Ioo inmates. At the other extreme, only 17 of the more than 600 workhouses could cater for I 000 or more. ${ }^{4}$ It is these huge institutions, found in London and a few other large cities, which people have in mind when they think of the workhouses as cavernous mausoleums with insatiable appetites for patients.

Through these institutions moved a mixed assortment of the society's disabled. Workhouse populations included orphaned children, widowed mothers, the sick of all ages and the chronically ill, the unemployed and the unemployable, the mentally defective and the crippled, along with the aged and homeless. Since alternative refuges did not exist in many districts, apart from a few voluntary hospitals and the asylums, the local workhouse continued to serve throughout the century as the only orphanage, fever ward, lying-in shelter, hospital and nursing home available in many communities. Yet despite this evident mixing of functions, the belief has grown up and persisted that workhouses were monopolised by the old.

This was not the case. In the middle decades of last century the aged formed a minor portion of any workhouse population. Many workhouses saw few or no aged persons at all for long periods of time. In i 851 less than $\mathrm{I}$ in 5 workhouse inmates was aged 65 or more. In the Southwest region the proportion did not reach $\mathrm{I}$ in 7 , while in Wales it was about $\mathrm{I}$ in $8 .{ }^{5}$ Children and the sick of all ages formed the bulk of the inmates.

This confusion about workhouses and the elderly is all the stranger in that another popular misconception is of a lack of old persons in the population of the past. A glance at the census returns should lay that shibboleth to rest. Persons aged $6_{5}$ and more in England and Wales totalled more than three-quarters of a million in ${ }^{8} 85 \mathrm{I}$, and more than one and a half million by the end of the century. In talking of the aged a century and more ago we are not talking about insignificant numbers of persons.

Two factors lie behind this muddle. The first is that London dominates and distorts the national reality. Despite the reforms of the 183 os the central Poor Law authorities throughout the following century had only a limited jurisdiction over local administrators. Variation from one workhouse to the next persisted, as each Board of Guardians was left to determine how large an institution it would build and operate, and how it would use its facilities. These variations were not random however. Important and enduring regional differences were apparent in the significance attached to workhouses. 


\section{Regional Variations}

At their simplest the regional disparities followed a North/South division. By the opening of the nineteenth century London had already earned the dubious distinction of placing an extreme emphasis upon large institutions as being the answer to all welfare needs. This peculiarity was to continue into the twentieth century, and was to affect a good deal of the nation's thinking on Poor Law matters. The counties around London adopted - and even exceeded - the metropolitan approach to individual welfare during the nineteenth century, and built workhouses which were large in relation to their populations. The further removed a district was from London, the smaller its institutions tended to be. Such counties as Kent, Sussex or Suffolk boasted one workhouse bed to every 40 or $5^{\circ}$ persons in the entire population, while Wales, the West Riding of Yorkshire, Durham and Northumberland furnished no more than one bed to every 150 or 200 persons in the region.

Further and perhaps more significantly, the various regions exhibited differing inclinations to use their workhouses in housing the old. Here again the huge and highly visible London workhouses were unusual. In I 85 I for example, I in 3 of London's 20,000 workhouse inmates was past the age of 65 , while in the rest of the country the numbers were about 15,000 out of a total of around 100,000 inmates, a ratio of perhaps I to 7. A 'national average', calculated at about $I$ in 5, represents neither the reality of London nor of the rest of the country.

The second factor behind the belief that workhouses were dominated by the elderly is confusion over time. As the nineteenth century progressed more and more groups amongst the disabled were removed from the workhouse, either to be provided for outside institutions altogether or to be treated in specialised facilities. By the early years of this century, in a growing number of districts, the casual wayfarer who sought a meal and a night's shelter, the expectant mother, the fever sufferer, the young, the mentally retarded, and the sick and injured had been excluded from the workhouse. The aged were left behind, along with other chronic patients, in institutions that were coming increasingly to look like the long-stay homes of residential care of our own day. Even by $189 \mathrm{I} I$ in every 3 workhouse inmates in England and Wales (including London) was aged $6_{5}$ or more: in London the figure was closer to $\mathrm{I}$ in 2, and a number of the metropolitan workhouses had been given over entirely to the care of the old. The workhouse became, more by default than design, the institution of the aged. The post-1 945 usage of former workhouses as geriatric homes and hospitals is simply a continuation of this long-term trend. 


\section{Levels of Occupancy}

A curious oddity of mid-nineteenth-century workhouses was their emptiness, in marked contrast both to popular belief and to twentiethcentury experiences of overcrowded facilities. The workhouses of a century ago seldom approached the point of being full, according to their registered capacities. On census night $185 \mathrm{I}$ the workhouses of England were about 60 per cent occupied: ten years later they were a little emptier still. Even in London only 3 in every 4 bed-spaces were occupied. Occupancy rates for many workhouses fell below 20 per cent, and across much of rural England around 4 in every 10 bed-spaces were occupied during the 1840 os and 1850 . Harassed administrators of hospitals and homes today might envy the flexibility this afforded the workhouse masters and matrons. If anything, a shortage rather than a superfluity of patients caused problems for the continued smooth functioning of many a nineteenth-century institution.

The changing seasons of the year made very little difference to this overall emptiness. Official counts of inmates were recorded on $I$ January and I July, so as to encompass both summer lows and winter peaks in welfare needs. ${ }^{6}$ Some variations in numbers did occur between the two dates, but the striking thing is how small the seasonal movement was. The old notion that hordes of the destitute, including the old, flooded into the workhouses in winter for warmth and shelter, and out into the countryside to cut grain or pick fruit in summer, is not substantiated by the records. Some individuals did migrate in and out of the workhouses, as any set of records will show, but their numbers were insignificant. Summer totals of inmates seldom fell below 9o per cent of the winter totals in the mid-nineteenth century, and by the end of the century this small margin of seasonality had all but disappeared. Counts of total patient-days spent indoors during the summer and winter months, rather than of individuals on selected nights, lead to an identical conclusion. ${ }^{7}$

The net effect of the modest sizes of workhouses, their emptiness and the mix of persons within them, was that the average workhouse of a century and more ago contained relatively few aged persons. At any one moment in the 1840 and 1850 os the 40 workhouses of Wales included about 4 aged women and 8 aged men apiece; the 70 or so workhouses of Yorkshire averaged no more than 6 aged women and ro aged men in each; and the 42 workhouses of the Northern region perhaps 7 aged women and 12 aged men. The numbers in workhouses elsewhere were only slightly higher. 
TABLE I. Percentages of the aged population of England and Wales in institutions, 185 I-1971

\begin{tabular}{|c|c|c|c|c|c|}
\hline \multirow[b]{3}{*}{ Date } & \multirow[b]{3}{*}{ Type of institution } & \multicolumn{4}{|c|}{ Age-sex group } \\
\hline & & \multicolumn{2}{|c|}{ Male } & \multicolumn{2}{|c|}{ Female } \\
\hline & & $65-74$ & $75+$ & $65-74$ & $75+$ \\
\hline 1851 & $\begin{array}{l}\text { All } \\
\text { Poor Law only } \\
\text { Hospital } \\
\text { Lunatic asylum }\end{array}$ & $\begin{array}{l}3.69 \\
3.43 \\
0.06 \\
0.20\end{array}$ & $\begin{array}{l}4.99 \\
4.87 \\
0.03 \\
0.09\end{array}$ & $\begin{array}{l}2.17 \\
1.95 \\
0.02 \\
0.20\end{array}$ & $\begin{array}{l}3 \cdot 3^{\circ} \\
3 \cdot 16 \\
0.02 \\
0.12\end{array}$ \\
\hline 1871 & $\begin{array}{l}\text { All } \\
\text { Poor Law only } \\
\text { Hospital } \\
\text { Lunatic asylum }\end{array}$ & $\begin{array}{l}4.70 \\
4.27 \\
0.08 \\
0.35\end{array}$ & $\begin{array}{l}6.71 \\
6.40 \\
0.06 \\
0.25\end{array}$ & $\begin{array}{l}2.59 \\
2.07 \\
0.08 \\
0.44\end{array}$ & $\begin{array}{l}3.95 \\
3 \cdot 54 \\
0.09 \\
0.32\end{array}$ \\
\hline $189 \mathrm{r}$ & $\begin{array}{l}\text { All } \\
\text { Poor Law only }\end{array}$ & $\begin{array}{l}5 \cdot 54 \\
4.94\end{array}$ & $\begin{array}{l}8.26 \\
7.83\end{array}$ & $\begin{array}{l}3.36 \\
2.63\end{array}$ & $\begin{array}{l}5.45 \\
4.8 \mathrm{I}\end{array}$ \\
\hline 1901 & $\begin{array}{l}\text { All } \\
\text { Poor Law only }\end{array}$ & $\begin{array}{l}6.4^{2} \\
5.82\end{array}$ & $\begin{array}{l}9.68 \\
9.25\end{array}$ & $\begin{array}{l}3 \cdot 54 \\
2.81\end{array}$ & $\begin{array}{l}6.26 \\
5.62\end{array}$ \\
\hline 1911 & $\begin{array}{l}\text { All } \\
\text { Poor Law only }\end{array}$ & $\begin{array}{l}7.03 \\
6.04\end{array}$ & $\begin{array}{l}8.30 \\
7.39\end{array}$ & $\begin{array}{l}3.47 \\
2.30\end{array}$ & $\begin{array}{l}5.60 \\
4.37\end{array}$ \\
\hline 1921 & $\begin{array}{l}\text { All } \\
\text { Poor Law only } \\
\text { Hospital } \\
\text { Lunatic asylum }\end{array}$ & $\begin{array}{l}4.02 \\
3.17 \\
0.20 \\
0.65\end{array}$ & $\begin{array}{l}5 \cdot 53 \\
4 \cdot 75 \\
0.23 \\
0.55\end{array}$ & $\begin{array}{l}2.48 \\
1.43 \\
0.22 \\
0.83\end{array}$ & $\begin{array}{l}4 \cdot 41 \\
3 \cdot 32 \\
0.35 \\
0.74\end{array}$ \\
\hline 1931 & $\begin{array}{l}\text { All } \\
\text { Poor Law only } \\
\text { Hospital and nursing home } \\
\text { Lunatic asylum }\end{array}$ & $\begin{array}{l}3.68 \\
2.44 \\
0.49 \\
0.75\end{array}$ & $\begin{array}{l}5.50 \\
4.05 \\
0.71 \\
0.74\end{array}$ & $\begin{array}{l}2.34 \\
0.96 \\
0.46 \\
0.92\end{array}$ & $\begin{array}{l}4.70 \\
2.71 \\
0.95 \\
1.04\end{array}$ \\
\hline I951 & $\begin{array}{l}\text { All } \\
\text { Home for aged and infirm } \\
\text { Hospitals and nursing homes } \\
\text { Homes for mentally ill }\end{array}$ & $\begin{array}{l}2.47 \\
0.74 \\
0.74 \\
0.99\end{array}$ & $\begin{array}{l}5.25 \\
2.30 \\
2.20 \\
0.75\end{array}$ & $\begin{array}{l}2.32 \\
0.45 \\
0.91 \\
0.96\end{array}$ & $\begin{array}{l}6.06 \\
2.19 \\
2.68 \\
1.19\end{array}$ \\
\hline ! $97 !$ & $\begin{array}{l}\text { All } \\
\text { Homes for old and disabled } \\
\text { Hospitals and homes } \\
\text { Psychiatric hospitals }\end{array}$ & $\begin{array}{l}2.27 \\
0.61 \\
1.02 \\
0.64\end{array}$ & $\begin{array}{l}6.96 \\
3.6 \mathrm{I} \\
2.55 \\
0.80\end{array}$ & $\begin{array}{l}2.38 \\
0.69 \\
0.95 \\
0.74\end{array}$ & $\begin{array}{r}10.17 \\
5.28 \\
3.58 \\
1.31\end{array}$ \\
\hline
\end{tabular}

Note: all figures have been calculated from the published census volumes for the appropriate years.

The tendency for official statistics to become less comprehensive towards the end of the nineteenth century has been commented upon in the text. This is apparent in the censuses of persons in institutions, $1891-1911$. In order to complete this table a small number of estimates have had to be made; the 1891 hospital figures are not given in the census, and the 1871 ones have been used here for 1891 ; the 1901 census does not give the ages of patients in lunatic asylums, and the 189 I figures have been used here for 1901 ; the 1901 census also fails to give ages of hospital patients, and the 1981 figures have been used once more; the 1911 census does not give ages of hospital patients, but this time the 1921 figures have been used to complete the gap for 1911 .

A number of very small twentieth-century institutions which house aged persons, mainly institutions for the blind, have been excluded from the calculations. 
One obvious implication of all this could be that $\mathrm{r}$ oo and more years ago institutional care for the aged was not important. If that was so, then it must be wondered when residential care was 'invented'. In Table $I$ are recorded the proportions of the aged population found in institutions at the various censuses since $185 \mathrm{I}$. We can at present do no more than speculate as to what the position had been prior to $185 \mathrm{I}$, and to wonder whether $185^{1}$ represented a unique or a normal point in the historic use of institutions.

A number of pertinent points emerge from this survey of 120 years. The first is the dominance of the workhouse in providing institutional care for the aged until well into the present century. Hospitals have begun to admit the aged in recent decades only, and the lunatic asylum housed far more of the aged than did the general hospital until the Second World War.

A second feature of Table $\mathrm{I}$ is that residential care does not appear to have been 'invented' at some stage during this period. Despite the comparative emptiness of a good many of the institutions of last century, the proportions of the elderly housed in workhouses a century and more ago were not too dissimilar from the proportions in institutions today. A third and related feature is that there has been no simple movement towards or away from residential care during this period. The tendency to put the aged into institutions grew during the second half of last century, to reach a peak in the opening years of this century. The numbers and proportions in institutions then fell away sharply during the First World War and the three decades following it. The years since I $95^{\circ}$ have seen a swing towards institutions once more, although those who are aged less than 75 years, formerly an important group in care, are now largely excluded from homes or hospitals of all sorts.

We shall consider later what might lie behind these patterns, but it may be remarked in passing that neither of our popular myths about old age in the past could derive unequivocal sustenance from these figures. With the single exception of the group of very aged females, fewer of the aged of today are in institutions of all types than were housed in workhouses a century and more ago - the time when 'the family' was somehow supposed to have been caring for and valuing their elderly. On the other hand, the belief that workhouses used to swallow up large numbers of the unfortunate aged gains only qualified support. The chances of an elderly person being resident in a workhouse 100 or more years ago were, with the exception of very aged women, little different from those of an aged person today being resident in a home, hospital or psychiatric institution. 


\section{Residential Care in Recent Times}

The recent movement of very elderly women into institutions is perhaps the most striking of the findings, since this is the one current development which appears to be without precedent. During the last 60 years the trend has been remarkable, while over the last two decades this mounting tendency to take elderly women into care has been nothing short of spectacular. There is every reason to believe that the 198 i census will confirm this trend. Moreover, this startling recent rise is not a result of the rising age of the retired population. It might have been suspected that what was being disguised in Table $I$ was a rise in the average age of those past 75, and that this rather than a rise in the incidence of residential care at any particular age, could account for the recent movement. This does not appear to be the case however. If the study is restricted to those past 80 or 85 the same trends are still observed. Census groupings at these very high ages have changed over the years, but the available figures are recorded in Table 2: the rapidity of contemporary changes is unmistakable.

These changes over the past century are the more striking still if the regional factor is kept in mind. London's workhouse record was never more atypical than with regard to aged women. In $18_{5}$ I for example, I 2.4 per cent or $I$ in 8 of all women past the age of 75 and living in London lived in a workhouse. This meant that elderly women in London were six times as likely to be in a workhouse as were women elsewhere, a disparity which diminished but remained into the present century. Care at these London levels went well beyond anything yet achieved by the country as a whole during its current rush towards institutions, and should give further pause to those who view the rise of residential care as some outrageous and very modern development. It might be more accurate to say that the rest of the country has spent the last century catching up with the capital. By $197 \mathrm{I}$ the metropolis had ceased to be remarkable with respect to aged women, and more than half the regions of the county had surpassed it in taking women into care. This regional variation of a century ago means that in many areas the changes in the housing of aged women during the present century have been much more spectacular than Tables $I$ and 2 would indicate, because their starting bases in r go I were lower than the national figures given here would imply.

This elimination of regional variation during the past century is apparent in all workhouse figures. The numbers of beds available and the numbers of aged men and women who occupy them have all been 
TABLE 2. Percentages of the population over 80 years of age in institutions, England and Wales, $185^{1-1971}$

\begin{tabular}{ccccc}
\hline & \multicolumn{4}{c}{ Age-sex group } \\
\cline { 2 - 5 } & & \multicolumn{2}{c}{ Male } & Female \\
\cline { 2 - 5 } Date & All 80+ & All $85+$ & All 80+ & All 85+ \\
\hline 1851 & - & 5.05 & - & 3.85 \\
1871 & - & 7.25 & - & 5.34 \\
1891 & - & 9.47 & - & 7.33 \\
1901 & - & 11.56 & - & 8.32 \\
1911 & - & 10.49 & - & 8.50 \\
1921 & - & 7.07 & - & 6.73 \\
1931 & 6.49 & - & 6.13 & - \\
1951 & 6.86 & - & 8.43 & - \\
1971 & 10.11 & 14.48 & 14.78 & 21.35 \\
\hline
\end{tabular}

Note: 'institutions' here means all Poor Law institutions, hospitals, nursing homes and psychiatric institutions. The notes for Table I also apply to this table.

standardized. Local peculiarities are still be be met, as Townsend discovered when he toured the country 20 years ago, but no significant regional patterns are now discernible on the scale of earlier years. ${ }^{8}$

The rising importance of the psychiatric hospital in the care of aged women is one further aspect of change which should be noted. A substantial number of women now find their way into psychiatric institutions in their last years, but unlike the hospitals, these institutions began to take in aged women towards the end of last century. The use of asylums to house the aged was essentially a late-nineteenth-century development. In 187 I lunatic asylums housed 35 per Io,000 and 44 per I 0,000 of men and women aged $65-74$ years, at a time when hospitals included a minuscule 8 per 10,000 of the same groups. By the beginning of the twentieth century the proportions in asylums had more than doubled, and have remained at a similar level to this day, except once again for the rise of very elderly women in asylum care.

The result of all this movement has been to turn the residential care of the aged into a feminine phenomenon, a complete reversal of the nineteenth-century balance in which males dominated. At the opening of the present century institutional care was still masculine, in terms of both numbers and proportions in care. By the 1970 s the priorities had been inverted. Aged women not only lived longer than did aged men, outnumbering men by 2 to I past aged 75, but also they each enjoyed a greater probability than did males of spending their last years in an institution.

This is about as far as published statistics will take us in putting figures 
to the past 120 years of residential care for the aged. There is very little to be learned from official compilations of the lengths of time spent indoors by elderly patients, the ages at which they were admitted, the numbers passing through institutions or the reasons for their being there at all. For answers to these questions our attention must switch to the manuscript registers of individual workhouses, which survive in large numbers in the County Record Offices. The Workhouse Admissions and Discharges Registers are the most comprehensive catalogues of patient details and movements on a day-to-day basis, and a wide variety of other workhouse registers survive to complement and extend the information carried in these volumes.

\section{Nineteenth-Century Institutional Life - The Bedford Workhouse}

An exploration of the Bedford workhouse registers will provide an illustration of what can be learned about institutional life from this type of record. The Indoor Relief Lists of Bedford provide in abbreviated form much of the detail carried in the Admissions and Discharges Registers, are perhaps the easiest and most useful class of workhouse registers to analyse, and constitute the basic materials for the following discussion. A set of Indoor Relief Lists for Bedford workhouse survives to cover almost every day from i 835 to 1927 , and other registers were available to fill the very few gaps. ${ }^{9}$ It was thus possible in these volumes to trace all movements into and out of the Bedford workhouse for the best part of $\mathrm{r} 00$ years.

Bedford was interesting for a variety of reasons. Its relatively large size, its mix of urban and rural parishes, its larger than average workhouse, and the absence for much of the nineteenth century of substantial institutions of alternative care, all made Bedford very typical of much of nineteenth-century England. Various comparisons made between Bedford and other districts and their workhouses all suggest that Bedford was fully representative of much of the country, and was not unusual in any extreme way. But if Bedford was typical, its interest was added to by the fact that its situation in rural England and close to London affords us the chance to observe residential care for the aged at something approaching a mid-century maximum. Bedford's experience was 'normal', but fell towards the upper end of the normal range. If the numbers spending time in Bedford workhouse seem small, we can be sure that they were greater than those for much of the country. 


\section{Numbers}

In the 1840 and 1850 persons aged 60 and more formed one-sixth of the Bedford workhouse population, or about 40 aged persons in an inmate total of 200-300. However, this elderly one-sixth accounted for one-quarter of all the patient-days spent inside, a reflection of the fact that in the nineteenth century as in the present the elderly tended to spend longer spells inside than did persons of other ages. By the Christmas of $184^{\circ}-1$ there were 19 men and 10 women past age 70 in the workhouse, along with 15 men and 7 women in their sixties. These aged persons represented a tiny fraction of all the Bedford aged, no more than about 4.5 per cent of all aged men and 2 per cent of all aged women in the district.

The workhouse relief lists for the 30 years following that Christmas were searched to see what happened to these elderly Bedford people. It appeared that perhaps I I 2 men and 62 women of the 690 men and 800 women who had been living in the union at the opening of $184 \mathrm{I}$ and who were aged 65 by the first day of $184 \mathrm{I}$, were to seek at least one night's shelter in the workhouse during those 30 years. ${ }^{10}$ That is, perhaps $I$ in 6 men and $I$ in $I 3$ women of the group who had already reached old age by $184 \mathrm{I}$, were to make an appearance at the workhouse before they died. A similar trace was made over 40 years of the cohort aged $55^{-6} 4$ at the opening of $184 \mathrm{I}$. This group numbered around 920 men and 1050 women, and 182 men and 97 women belonging to this age group were to turn up in the workhouse by $\mathrm{I} 88 \mathrm{I}$. This meant that, at the most, perhaps $I$ in 5 of the middle-aged men and $I$ in I I of the middle-aged women were ever to become workhouse inmates.

These proportions are not nearly as high as popular accounts of the ending of life in a workhouse would have us believe. But more than that, the suggestion that perhaps $I$ in 5 and $I$ in 12 women who reached old age would spend a night in a workhouse is far too generous and incautious an estimate of the reality. The true proportions may have been no more than half of these, even in Bedford where the old were sent to the workhouse with greater regularity than elsewhere.

Calculations such as these are subject to two major uncertainties. The first concerns age. At admission in Bedford the birth-year of the new patient was recorded. This gives the impression of certainty, but in all likelihood the new arrival was asked his or her age, and the master or the clerk completing the record converted this into the form required. The important point to remember is that the new entrant had very good reasons for claiming an advanced age. Persons past 60 years of age were considered 'old' under nineteenth-century workhouse rules, and 'old 
age' brought with it exemptions from numerous rules governing diet, medical attention, uniforms, work, alcohol, snuff, tobacco and permits for leave. The higher the age of an inmate the greater the leniency with these exemptions. It seems highly probable therefore that some persons who had not been aged 65 or more in 1841 , would arrive at the workhouse many years later and claim to be old enough to belong to that cohort. If these exaggerators of age could be weeded out, then the proportions calculated to have ever entered an institution would fall.

\section{Mobility}

A second source of uncertainty was mobility amongst the elderly. Under the procedure adopted here everyone who appeared at the workhouse is assumed to have been a resident of Bedford, and never to have been in any other workhouse but the Bedford one. Census and Poor Law records reveal however that aged persons moved about the country a good deal, so that the arrival at Bedford workhouse of non-residents, or of aged persons who had been in other workhouses, cannot have been uncommon. The workhouse records themselves provide no check on this, for it appears that whenever the place from which a new patient had come was unclear, the Bedford Master wrote in 'Common Charge' or 'St Paul', the name of the largest and poorest of the urban parishes. The proportions calculated here for those who would ever enter a workhouse must include a good deal of unavoidable double-counting. Men who formed part of the $\mathrm{I}$ in 5 or $\mathrm{I}$ in 6 who would enter the Bedford workhouse, for example, may very well have passed through several other workhouses and so formed part of the $\mathrm{I}$ in 6 or whatever that would be calculated by this method to have entered other workhouses. The double-counting is extremely difficult to check, and we have little way of knowing what uncertainty may have crept into our calculations. An aged man who entered the Bedford workhouse in i 869 , for example, and who gave his age then as 83 , will under the rules adopted here be considered as one of the 920 men who had lived in Bedford in $184 \mathrm{I}$ and who had been aged $55^{-6} 4$ at that date. The likelihood that he might not have been living in Bedford then, that he might not have been counted as $55^{-64}$ in $184 \mathrm{I}$, or that he might have visited other workhouses and so boosted the inmate counts elsewhere, must have been quite high.

This 'incautious' approach to workhouse admission has been followed so that our estimates will represent the very upper limits of the probability of entry into a workhouse in old age. The calculation that perhaps $I$ in 5 men and $I$ in I I women who reached old age would ever 
enter an institution represents a very generous estimate of the possibility. The great majority of the ageing in Bedford would never see the inside of a workhouse. This was true, moreover, of one of the most vulnerable groups in the whole country - men and women reaching old age in an impoverished, southern rural community. The chances of ever entering a workhouse must have been slim elsewhere. The fear of being removed to a workhouse in old age may have been very real, but across much of the country the chances of it ever happening must have been small indeed.

\section{Characteristics of residents}

Workhouse registers are not good at revealing which groups amongst the old would enter a workhouse. The comments upon occupations which some Masters recorded from time to time suggest, much as would have been expected, that it was the poor and the unskilled of the community who were to be found in these places, although every set of workhouse registers exhibits its occasional 'fallen' schoolmaster, solicitor or businessman. Townsend's research in the ig6os revealed that a similar occupational discrimination is still to be discerned in the selection of patients for the different types of institutions. Perhaps more disappointing here was the weakness of the workhouse records with regard to the familial and marital status of elderly inmates. Townsend was able to demonstrate that it is the widowed, the never-married and the family-less who stand the greatest chances of entering institutions in old age. It seems likely that the same was true a century and more ago, but it has not been possible to test this fully. Comments upon family are very incomplete in workhouse records, and even the registering of marital status is uneven. The only distinction which can be established with some certainty is that between those entering with a spouse and those entering alone.

One of the great nineteenth-century public concerns, and one that was carried over into the present century, was the treatment of the married in the workhouse. The standard popular opinion was that marriage partners were always separated upon entry, that this constituted a gross violation of family life, and that loathing of this treatment lay at the root of working-class abhorrence of the Poor Law. Evidence of the strength of feeling on the issue is abundant. The 'riots' in the workhouse, the smashing of windows and furniture, and the workhouse Master's need to call in the Bedford police in the early 1840 s is but a single instance of the passion that could be arroused by the separation of husband and wife, apparently a new procedure in Bedford around I $840 .{ }^{11}$ 
That this separation should be enforced upon aged couples in the workhouse was held by a very great many to be one of the ultimate indignities of the Poor Law, and a sign of the fundamental inhumanity of the new, post-I 834 regime. On the other hand, the administrators of the New Poor Law moved quickly to defuse the anger engendered. The Commissioners in London directed that when both partners were over 60 they should be given a room in the workhouse to share in private, should they ask for it. ${ }^{12}$ From the late 1840 a private room became the right of every aged couple: when one partner alone was past 60 , the local authorities were to use their discretion in the granting of rooms. ${ }^{13}$

It is difficult to tell where the truth lies on this whole question of separation of aged couples. The popular opinion remained for a century and more that aged couples were always separated upon admission, no matter what officials might claim to the contrary. The official position remained equally firmly that very few aged couples were in fact ever to be found in a workhouse, and that separation was not required. Their argument was that aged couples were maintained on outdoor pensions of a few shillings a week for as long as this was at all possible, and that when it was finally necessary to bring the aged couple in to the institution, the patients nearly always had to live apart because of illness, or chose to do so.

The few available figures give some support for the official position. Aged couples were seldom found in the workhouses. A survey of the workhouses of England and Wales in 1853 , for example, revealed a total of 873 aged couples spread amongst the more than 600 institutions. The private rooms which most workhouses made available had to be put to other uses, since of these 873 couples only about $\mathrm{I}$ in 3 shared a room. Amongst the reasons given by officials for their failure to persuade more aged couples to share a room together were the following: 'wife in infirmary', 'female in sick ward', 'husband ill and in infirmary', 'on account of illness', 'haven't lived together for 20 years', 'on own request', 'from choice', 'refused live together', 'request be separated', and 'not lived together several years'. ${ }^{14}$

All records of individual workhouses confirm official claims that aged couples in institutions were a rarity. The Bedford workhouse, for instance, boasted 2 aged couples at the opening of $184 \mathrm{I}$, and the figure seems to have reached an all-time peak of 5 in 1842 . At that point the decision was taken to make private rooms available, and 4 couples chose to use them. The pressures upon these rooms can never have been great. Of the 1,700 men and 1,900 women in the union and aged 55 or more in 1841 , not more than $3^{8}$ men and 28 women were to appear at the workhouse with a spouse during the next 40 years. In all, 22 aged 
couples from this cohort entered when both partners were past age 60 . The periods which these 22 couples spent indoors varied enormously, but in a handful of instances only did the couple spend more than a few weeks in the institution. No record survives to tell whether they chose to share rooms or not. The fact that most of these couples moved in and out of the workhouse quickly, or that one of the partners died soon after admission, furnishes further backing for the claim that the housing of aged couples in the workhouse was not a normal option, but that aged couples came in only when extreme circumstances made this unavoidable.

The cleavage between popular belief and official evidence remains, and feeling on the issue was always high. But whatever the truth of treatment in the workhouse, the numbers of aged couples involved cannot have been large. The married elderly were all but excluded from residential care. Institutional life in old age was for the never-married, the widowed and the separated. During a century and more, very little has changed in this regard.

\section{Age}

Those who entered Bedford workhouse in old age did so at ages ranging from the mid-fifties to the mid-nineties. Table 3 presents an analysis of the ages at admission of the group who were aged $55^{-64}$ in $184 \mathrm{I}$. The table can provide no more than a general summary of mixed data which is difficult to reduce to a few statistical categories. All persons in the workhouse at the opening of $184 \mathrm{r}$ have had to be excluded. For the rest it had to be assumed that the first recorded admission after age 55 was the first admission for that person, when in fact the new entrant may have visited the workhouse many times in earlier years. In some instances the procedure adopted here could distort the reality badly, and the case of Elisabeth Garrett provides an extreme illustration of this. In 1847 she spent 13 days in the workhouse, when aged 63 . She did not reappear for 18 years, until $\mathrm{I} 86_{5}$, when at a recorded age of $8_{3}$ she was to spend 18 months in the workhouse before dying there. Under the rules of classification used here she is considered to have started her 'workhouse career' at age 63 . Such cases were fortunately very rare, but the point to be kept in mind is the great diversity of experiences observed. One aged person would spend 25 years in the institution before dying there, while the next patient admitted could well spend two days inside before leaving, never to return.

The most striking thing about these ages at admission is how young the new patients were. Almost two-thirds of those who were going to 
TABLE 3. Summary of the ages at which those aged 55-64 in $18_{4} I$ entered the Bedford workhouse, $184^{1-1} 881$

\begin{tabular}{ccc}
\hline $\begin{array}{c}\text { Percentages of all admissions } \\
\text { fom this cohort }(\mathcal{N}=169 \text { men, } \\
99 \text { women) which occured at } \\
\text { the age shown }\end{array}$ \\
\cline { 2 - 4 } Age & Male & Female \\
\hline $55-9$ & 6 & 8 \\
$60-4$ & 36 & 30 \\
$65-9$ & 22 & 19 \\
$70-4$ & 16 & 11 \\
$75-9$ & 10 & 17 \\
$80-4$ & 5 & 11 \\
$85+$ & 5 & 4 \\
& -100 & 100 \\
\hline
\end{tabular}

Note: 1 i men and 8 women aged $55^{-6} 4$ in 1841 , who were already in the workhouse at the opening of $184 t$, have been excluded from this count.

enter the workhouse in old age had done so by age 7o. In our own day ages at admission are very much higher than this. When Townsend surveyed a sample of 530 new admissions to institutions in the early i 960 , he found that only io per cent had been admitted before age $70 ; 47$ per cent had been admitted when aged between 70 and 79 years, and almost half had been admitted when past age 80. ${ }^{15}$ Amelia Harris recorded similarly in 1968 , in surveying the aged in 9 sample regions of England and Wales, that 68 per cent of the patients of institutions had been 75 years or more of age at admission. ${ }^{16}$ In the present an aged person is unlikely to be admitted to an institution before age 75: a century ago a person who had not visited an institution by that age was unlikely ever to do so. The nineteenth-century institution was evidently serving some different functions from those of its twentieth-century successors.

This differing of functions is pointed to by two further analyses of the Bedford experience. Death in the workhouse was rare. The fear of dying in the workhouse is perhaps one of the most enduring of memories from the Poor Law era, but as in so much else, the dread of the possibility was far more pervasive than the actuality. The image of workhouses as places of endless death amidst squalor and indifference enjoys little real basis. The 'average' workhouse of a century ago contained few of the dying, and months could often pass between one workhouse death and the next.

In Bedford workhouse, for example, an average of $30-35$ deaths 
occurred each year in the 1840 os and 1850 os. Of these about 12 a year were of persons past the age of 60 , and the remainder included many stillbirths or deaths of infants within a few hours of birth. Twelve deaths a year in Bedford workhouse meant that less than $\mathrm{I}$ in $\mathrm{I}$ o of all deaths in old age in Bedford union was taking place within the workhouse. ${ }^{17}$ The same was true elsewhere. Four persons past age 60 died in the Leighton Buzzard (Bedfordshire) workhouse in 1859 , the first year for which records survive: 6 aged persons died there in $\mathrm{I} 860,8$ in I86 I, and 9 in $1862 .{ }^{18}$ The workhouse of Ipswich (Suffolk) saw an average of 30 deaths a year throughout the mid-nineteenth century, with about 15 a year being of persons past age $60 .{ }^{19}$ Again, as at Bedford, these formed less than $\mathrm{I}$ in $\mathrm{I} O$ of all deaths in the district. It was rare for aged women ever to die in the Ipswich workhouse: 5 who were past age 60 did so in 1840 . in 1841 the number was 2 , in 1842 it was $I$, in 1843 3 , and in 18442 . At the Tattingstone workhouse of the Samford Union (Suffolk) an average of 13 aged persons died each year in the 18505 , with men again outnumbering women two to one. ${ }^{20}$ Across the country, at the Warwick workhouse, the annual toll was about 28 , with 16 of these being persons past $60 .{ }^{21}$ And thus the examples may be continued. It may be noted too that these workhouses, all in the 300- to 500-bed range, were larger than average for the nineteenth century.

The tracing of the 'workhouse careers' of the ageing Bedford cohorts had a similar outcome. Less than half of those who would ever enter the workhouse in old age would die there. At the very most, perhaps 7 per cent of the male cohort aged $55^{-64}$ in $184_{1}$ would die in the workhouse, a total of 65 men from a group of 920 . Amongst women of the same cohort the proportions dying in the workhouse were perhaps 4 per cent, or 42 from a group of 1,050 . The removal of death from the home to an institution is something which has occurred during the last I 00 years - it was not a phenomenon apparent a century and more ago.

One further analysis which brings out the point that nineteenth-and twentieth-century institutions have served differing functions is that of the lengths of time being spent inside. A number of simplifying procedures had to be used in order to standardise these disparate experiences. Even then the count could not include those who were already in the workhouse at the opening of $184 \mathrm{I}$. However, some general idea of the time being spent indoors could be gained by counting the numbers of days each patient stayed in the workhouse, regardless of the number or length of breaks which might occur between spells in the institution. Table 4 presents a record of the experiences of the cohort aged $55^{-6} 6$ in $\mathrm{I} 84 \mathrm{I}$.

By twentieth-century standards these men and women were spending 
TABLE 4. Summary of the lengths of time spent in the Bedford workhouse between $184 I$ and $I 88 I$, by all those aged $55+$ in $184 I$

(The figures in the table are for the percentages of this cohort who spent the period shown in the workhouse.)

\begin{tabular}{|c|c|c|c|c|c|c|}
\hline \multirow[b]{3}{*}{ Length of time spent indoors } & \multicolumn{6}{|c|}{ Age at admission } \\
\hline & \multicolumn{3}{|c|}{ Male } & \multicolumn{3}{|c|}{ Female } \\
\hline & $60-9$ & $70-9$ & $80+$ & $6 o-9$ & $70-9$ & $80+$ \\
\hline Up to 7 days & 15 & 10 & 6.5 & II & 10 & 7.5 \\
\hline 8-3o days & 20 & 22 & I3 & 16 & I0 & 5 \\
\hline $3^{I-I}-100$ days & 17 & 24 & 34 & 7 & 22 & 27.5 \\
\hline $101-365$ days & 19 & 15 & 24 & 25 & 24 & 17.5 \\
\hline Over $I$ and under 3 years & 6.5 & 14 & 15 & 16 & 26 & 30 \\
\hline Over 3 and under 6 years & & 9 & 6.5 & 16 & 2 & 12.5 \\
\hline Over 6 and under to years & 6.5 & 7 & 4 & 7 & 4 & - \\
\hline Over ro years & 7 & $i$ & 一 & 2 & 2 & - \\
\hline All lengths & 100 & Ioo & 100 & roo & 100 & 100 \\
\hline Percentage less than I year & 71 & $7 \mathbf{I}$ & $77 \cdot 5$ & 59 & 66 & $57 \cdot 5$ \\
\hline $\begin{array}{l}\text { Average number of days } \\
\text { indoors }\end{array}$ & 763 & 469 & 317 & 696 & $4^{18}$ & 405 \\
\hline No. in sample & 94 & 94 & 47 & 43 & 50 & 40 \\
\hline
\end{tabular}

Note: those already in the workhouse at the opening of $18_{4}$ I have been excluded from the count.

very little time in the institution. Three in every four men who would enter the Bedford workhouse in old age were spending less than $3^{6} 5$ days indoors in total, as were two in every three of the aged women who entered. Twenty years ago Townsend found that three in every four persons he interviewed had already spent at least a year in an institution $:^{22}$ a count of all the days spent in institutions of all sorts in old age in the later twentieth century would produce results that are simply not comparable with those from the nineteenth century. Nor has increased longevity played a significant part in the change. In the century which elapsed between the experiences in Bedford being examined here and the experiences reported upon by Townsend, life expectation for men of $6_{5}$ had increased by less than one year, for women of 65 by about 3 years. ${ }^{23}$ Death did not come much sooner to the old of a century ago than it does to the old of today. The change in lengths of time spent inside cannot be explained by a lengthening of old age.

\section{Deductions from the Bedford Experience}

The analysis suggests that a number of features of residential care have changed over the century. Further investigation indicates that these 
shifts in behaviour must have taken place fairly recently. Traces of the experiences of several ageing cohorts of Bedford residents were made in a manner identical to that described above, for the groups aged $55^{-64}$ and 65 and more at the opening of $187 \mathrm{I}$, and of $189 \mathrm{I}$. The surprising and unexpected finding was that very little changed. In Bedford, as elsewhere, the aged population grew in number, so that by the end of the century there were twice as many aged persons living in the union as had been there half a century earlier. Since the workhouse had not been altered significantly, the result was an institution with a large aged component amongst its inmates, all of which gave the impression of a massive and extended institutionalisation of the elderly. However, the ages at which the elderly entered the workhouse, and the periods which they spent inside, had altered almost not at all. Some differences did emerge, but the conclusions reached for the cohorts of i 84 I remained broadly true for the best part of a century.

Three changes which occurred over the 90 years from I 840 may be singled out for comment. In the first place, although the proportions of males who would ever enter the institution remained remarkably stable, the figures may have risen for aged women. Of those men aged 55-64 in I84I, I87 I and I89I, around 20 per cent of each group apeared likely to experience some time in the workhouse during old age. The corresponding proportions for women rose from around 9 per cent in $184 \mathrm{I}$, to perhaps 10 per cent in $\mathrm{I} 87 \mathrm{I}$ and $\mathrm{I} 3$ per cent for the group reaching old age in the 1890 and early 1900 . However, it is always quite possible that the uncertainties inherent in our procedures and records could account for this small degree of apparent change.

A second feature of note was the gradual disappearance during the nineteenth century of itinerant workhouse admissions and discharges. By the end of the century few inmates of any age were to be found wandering in and out of workhouses. People ceased to treat admission lightly, and went indoors only when sickness or decrepitude made this unavoidable. This reluctance to enter, in an era which saw a slight worsening in the health and mortality of the aged, ${ }^{24}$ would have had the effect of keeping stays indoors short. It would have had the effect too, we might suspect, of raising the incidence of death within the workhouse.

This last did occur, and constitutes the third of the noteworthy shifts over time. The likelihood of dying in the Bedford workhouse in old age was greater by the end of the century than it had been half a century earlier. Of the men aged $55^{-64}$ in 1841 who would ever enter the workhouse, 39 per cent were to die there: the figures for the cohorts of 1871 and 1891 were $5^{8}$ and $5^{6}$ per cent. Amongst women the 
comparable changes were from 53 to 67 and 74 per cent. Escape from the workhouse, other than by death, was becoming increasingly rare. This shift meant that a rising proportion of all aged persons were dying in the workhouse. About 7 per cent of the male cohort aged $55^{-64}$ in 1841 had died in the workhouse: for the cohorts of 1871 and 1891 the figures were around II per cent. For women the rise in workhouse deaths was more striking, from about 4.5 per cent in $184 \mathrm{I}$ to 7 per cent in 1871 and 10 per cent in 1891 . The Bedford rise in workhouse deaths seems to have been repeated throughout the country - during the later nineteenth century death was already in the process of being removed to an institution.

\section{A Century of Residential Care}

The research upon workhouses has pointed to a number of important shifts in residential care during a century or so, the most interesting of these perhaps being the swing from institutions dominated by males to institutions of females, the disappearance of regional variation, the rising ages of inmates, the virtual exclusion of the 'young-old' from institutions, the increasing lengths of time being spent indoors, and the mounting tendency for deaths to occur away from the home. More research upon contemporary institutions would offer additional bases for comparison with these historical materials, but in ending the discussion it is worth speculating upon what lies behind these patterns. Is there any one thing which might link all of these features?

The 'decline in family life' could provide perhaps one ready and plausible linkage. Changes in family life and sizes, increased mobility, new occupational patterns, retirement policies, new expectations of privacy, space and material satisfaction, perhaps a rising selfishness and a tendency to see responsibility for the elderly as lodging elsewhere than with relatives, could all possibly be woven into a feasible network of cause and effect. But this recourse to the popular myth would need to be developed with considerable sophistication, and more importantly, with a close regard for the larger social context within which 'families' have to live and operate.

A second potential line of explanation, more promising of firm and verifiable conclusions than is the grand synthesis of the popular tradition, is an emphasis upon the varying functions of institutions of care. A present-day institution meets numerous and diverse needs. Elderly patients enter such places for all sorts of reasons, medical, social, economic, psychological and emotional. Similar pressures, in varying 
mixes, brought aged persons into the workhouses of a century ago, and in an examination of the roles of workhouse and nursing home might lie the means to link the changes in institutional life which have been noted. Such an approach lacks an essential focus, however, a focus which can be provided by one further and little-explored facet of the history of old age - the economics of old age.

During the middle decades of the nineteenth century between one-half and three-quarters of all Englishwomen aged 70 or more received a regular weekly pension of about $2 s .3^{d}$. to $3 s$. a week. Elderly women were not expected to possess resources of their own, but were paid what amounted to an old age pension, a Poor Law allowance which was funded by a local tax upon property. Aged men were treated much less kindly, with somewhere between one-quarter and one-half of all aged men being regular pensioners. In southern and rural England the proportions assisted were at their highest: in London, and to a lesser extent in urban-industrial England, the proportions maintained were at their lowest. While the society displayed a strong willingness to maintain women past 70 , and men past 70 to a lesser degree, it appears however to have felt little compulsion to pension those still in their sixties. Persons aged less than about 67 seem to have been considered 'of working age' and capable of making a living of their own. Very few men in their early or mid-sixties received monetary assistance, and although the numbers of women in their sixties who were pensioned could vary greatly, they nowhere reached the levels current amongst those aged 70 and more. ${ }^{25}$

Maintenance of the elderly in institutions was and remains a counterpart to maintenance of the old by means of cash pensions, and variations in institutional experiences over a century and more can be shown to have a functional relationship with the availability and value of pensions. A pension of $2 s .6 d$. or $3 s$. a week in mid-nineteenth-century England assured the elderly beneficiary of anything from 60 to 100 per cent or more of the average weekly income available to non-aged, working-class adults, and was ample for the maintenance of an independent existence at the standards accepted at that time. ${ }^{26}$ Women from their late sixties on had little need of recourse to an institution, until failing physical or mental health precluded the option of continued private living. Elderly women might live with their families, but the matter was one of choice. They had little financial need to do so, and a matching of Poor Law and census materials suggests that women with pensions in the mid-nineteenth century did not choose to live with relatives any more than do elderly women with pensions of comparable worth in the twentieth century. When they did choose to live with 
others, elderly women with pensions could often be a financial asset to the household, and were often helping out young relatives as much as they were being 'maintained' by the young. Elderly men by contrast enjoyed less of this freedom afforded by financial independence, and had more often to succumb to the pressure to take shelter in an institution.

During the last decades of the nineteenth century this system of Poor Law pensions broke down under the assault of a powerful group of Poor Law and charity reformers, who instigated a campaign to replace maintenance by pensions with maintenance by family or in the workhouse. Between 1870 and 1890 the proportions of the elderly assisted by pensions were more than halved, and the effective relative value of an end-of-century pension - when it was still available - was no more than one-half to one-third of that of a mid-century pension. Poor Law pensions would no longer ensure an independent existence, and while some of those 'dispossessed' of their pensions found other means of subsistence, increasing numbers of the old were forced to rely upon workhouses in their last years. The result was the rise in the proportions in institutions, and because the pensions available to men were cut more savagely than those to women, male numbers in institutions remained well above those of females.

In 1908, with the passing of the Old Age Pension Act, Britain began the slow re-introduction of a system of pensions for the elderly. Elderly persons were once more afforded an alternative to reliance upon relatives or the workhouse, and a rapid decline in the proportions in institutions took place. Manpower needs during two world wars boosted the economic resources of ageing persons, while the raising of the old age pension to IOs. a week from I 9 I 7 ensured that during the dark days of the r 920 s and r 930 s the elderly enjoyed an assured income of comparatively stable relative value. The pre- 1945 state old age pension amounted to about $40-50$ per cent of the weekly income of the average working-class adult, well below the relative value of a mid-nineteenthcentury pension but equal to or better than the value of any post-1 945 pension.

Since 1945 the economic position of elderly persons has deteriorated badly. The true value of pensions has fallen steadily and unrelentingly, in that elderly persons in Britain now have a living standard which falls further and further behind that of the non-aged community. The Retirement Pension has remained 'fixed' in value at about 40 per cent of the income of the average non-aged working-class adult, but this apparent changelessness masks an unmistakable decline in the overall economic resources of the old. The basic pension may have held its relative value in certain respects, but the total 'package' of incomes 
which the elderly enjoy, drawn from pensions, benefits, employment, occupational superannuations, investments, rents and the like has had its value eroded. This declining access to the resources of society on the part of the elderly can be measured in a number of ways, all of them complicated and of varying degrees of worth and inadequacy, but the best ready measure of decline is perhaps the expenditure-plus-savings which different groups in the community are able to indulge in, as reported in the annual Family Expenditure Surveys. At the time of the I 953-4 survey, the first of the postwar era, the average British resident past the age of 65 lived in a household in which all adults spent or saved $8 \mathrm{r}$ s. a week. Persons of less than 65 years, by contrast, lived in households with an average adult expenditure-plus-savings rate of $98 s$. a week. ${ }^{27}$ This meant that the average person past 65 had resources equal to 83 per cent of those of the non-aged. By the end of the 1970 , despite growing state and private pension and superannuation schemes, elderly expenditure-plus-savings amounted to no more than 68 per cent of those of the non-elderly, and there are very good reasons for thinking that the difference between old and young by 1979 was in fact much greater than this 68 per cent would suggest. ${ }^{28}$ Allowances made for growing health and welfare expenditures upon the elderly do not alter the pattern of decline substantially.

The effect of this development has been that the continued independent living of increasing numbers of elderly persons is under threat, and the rise once more in the numbers in institutions is the inevitable partner of this unhappy trend. The differing economic fortunes of various groups are reflected in the figures for institutions. Elderly men have done rather better than have elderly women in avoiding or at least slowing the decline in their economic position vis-à-vis the rest of the community, largely because the expansion of occupational and contributory pension schemes since 1945 has benefited them far more than their widows or unmarried sisters. The 'young-old', too, have fared rather better than have the 'old-old'. In the nineteenth century more generous pensions were available to the very elderly than to the not-so-elderly. Post- 945 Britain has seen a complete reversal of these priorities, with the social security system all but refusing to recognise any age distinctions beyond 60 , with the erosion by inflation in recent years of the assets and private pensions of the very old, and with the means of the 'young-old' and recently retired to benefit from newer and more generous, often inflation-proofed pensions.

The tumbling overall value of pensions, their availability and relative worth to men and women and to the elderly and the not-so-elderly, and regional variations in the economic resources of the aged, can all be 
related closely to the patterns of institutionalisation discussed in this paper. During the past 120 years life in institutions and the availability of publicly funded alternatives to institutions in old age have borne an intimate and consistent relationship. The 'lesson' from this, if lessons are ever learned from history, is that the declining true value of pensions in the 1950s, I 960 and 1970 is the cause of the rising numbers of the elderly in institutions. Unless the incomes of the elderly in general, and of elderly women in particular, can be given a significant boost these trends can only continue. This must be a worrying prospect, for all the indications are that governments of the 1980 s are not going to increase substantially the incomes of elderly persons. The cycle has a further troubling aspect. As the economic resources of the elderly decline, more and more of them are unable to maintain an independent life, the numbers in institutions rise, and the costs of maintaining the elderly population appear to soar. But as this happens, the amounts of money made available by society to the elderly as a whole do not rise by any commensurate amount, so that rising numbers of the elderly in institutions are in effect financed by further cuts in the incomes of the non-institutionalised aged. With this comes greater pressure upon the continued independent existence of more elderly households, and so the screw tightens. The way to reverse the current trend towards taking large numbers of the elderly into expensive care in hospitals and homes, would seen to be to put more money into the pockets of the elderly who live in private households, but this society seems quite unwilling to countenance.

\section{NOTES}

I The standard history of the Poor Law and its workhouses is still Webb, S. \& B., English Poor Law History, Longmans, London, 1929.

2 A substantial portion of the argument and detail of this paper is drawn from D. Thomson, 'Provision for the elderly in England 1830 to 1908 ', PhD dissertation, University of Cambridge, 1980 .

3 The most useful guide available to the many classes of Poor Law records is Part I of Somerset County Council, Records Committee, $A$ handlist of the records of the Boards of Guardians in the County of Somerset, Somerset County Council, Taunton, 1949.

4 Return... of the amount of workhouse accommodation in each Poor Law Union, for the year ending 31 December 1854 : Parliamentary Papers (hereafter PP) $1854^{-5}$, xLvi.

5 Unless stated otherwise, all figures of populations and their ages used in this paper are derived from the published census volumes for $1851,186 \mathrm{I}$, and subsequent Io-yearly censuses. Subsequent references to this source will not be acknowledged.

6 The 1 January and I July numbers of persons in workhouses are given in the annual reports of the Poor Law Commissioners (to 1847 ), the Poor Law Board (to 1871 ), and the Local Government Board (from 1871 ). 
7 Calculations of the patient-days spent in workhouses have been made from the manuscript registers of individual workhouses.

8 Townsend, P. The Last Refuge - a survey of residential homes for the aged in England and Wales, Routledge and Kegan Paul, London, 1962, tables A-C, pp. 505-15.

9 Indoor Relief Lists, Bedford Union, 1836-1927, and Admissions and Discharges Registers, Bedford Union, 1836-1929: Bedfordshire County Record Office classes PUBR 1 and PUBV 1 .

Io The ${ }_{1} 8_{4}$ I census does not give populations according to Registration Districts, which were identical in all but name to the Poor Law unions - in 1841 these new units of administration were still too new and untried to be accepted by the census takers. The 1841 populations of Poor Law unions have here been calculated from a mixture of 1841 and 1851 materials.

I I Master's Report and Journal, Bedford Union, 1842-4: Bedfordshire CRO class PUBV 6. The Workhouse Master attributed the whole of the disturbances in the workhouse in the early 1840 s to the separation of husbands and wives.

12 Third Annual Report, Poor Law Commissioners, p. 37: PP I837, xxI. The position was further clarified in a return titled Workhouse Rules, p. 5: PP 1844 , XL.

13 The legal position on the separation of aged couples is summarised in appendix II, Report of the Royal Commission on the Aged Poor: PP I 895 xrv.

14 Two official returns were prepared on this question: Return of the number of married couples above sixty years who are inmates of workhouses: PP 1852-3 LXXXIV, and Return of unions in England and Wales which have acceded to the non-separation of aged couples: PP 1 863, LII.

15 Townsend, op. cit. table 55, p. 279.

16 Harris, A. Social Welfare for the Elderly, HMSO, London, 1968, vol. I, table 30, p. 92.

17 Workhouse Death Register, Bedford Union, 1835-42: Bedfordshire CRO class PUBV 37. The numbers of deaths occurring at different ages in the various unions are all available in the Annual Reports of the Registrar-General of Births, Deaths and Marriages.

I 8 Workhouse Deaths Registers, Leighton Buzzard Union: Bedfordshire CRO class PULBV 27.

I9 Workhouse Deaths Registers, Ipswich Union: East Suffolk CRO class DDl/44/3.

20 Workhouse Deaths Registers, Samford Union: East Suffolk CRO class $\mathrm{ADA}_{7} / \mathrm{CB}_{3}$.

2 I Workhouse Deaths Registers, Warwick Union: Warwickshire CRO class CR 5 I.

22 Townsend, op. cit. table i 10, p. 528.

23 The most complete guide to the subject of life expectation and its changes over time is available in the Supplementary Reports which the Registrar-General issued from time to time, in conjunction with his Annual Reports. A useful introduction to the statistics of life expectancy is Benjamin, B. Health and Vital Statistics, Allen and Unwin, London, I968, pp. 92-1 15 .

24 The changing course of mortality rates, $1840-1970$, can be traced in RegistrarGeneral, Statistical Review of England and Wales, for the year I97 I, pt I, table 4.

25 All of these points have been developed more fully in Thomson, op. cit.

26 The analysis of the changing values of pensions is an extension of the original doctoral research, and has been undertaken during 1982 as part of a rewriting of the earlier work in preparation for publication. A term as Post-Doctoral Fellow at Victoria University of Wellington, New Zealand, has made this rewriting possible.

The source of the calculation of pension values is an assemblage of 25 'family expenditure surveys', dating from 1837 to 1979 . From these the average resources 
available to English men and women have been recalculated, and it is against these estimates of average incomes that the value of a contemporary pension can be measured.

27 Ministry of Labour. Cost of Living Advisory Committee, Report of an enquiry into Household Expenditure, 1953-4. HMSO, London, I957, table 8.

28 Department of Employment, Family Expendilure Survey, for 1979, HMSO, London, I980, table 6 . 